\title{
Integrones y su relación con el fenotipo de resistencia en bacilos gramnegativos aislados en el Hospital Torres Galdames de Iquique, Chile
}

\author{
Rubén Moraga M., Edgardo Santander P., Teresa Arias C. y Fermín Méndez A.
}

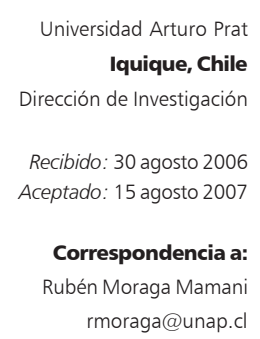

Correspondencia a:
Rubén Moraga Mamani rmoraga@unap.cl

\section{Integrons and their relationship with resistance phenotype in Gram negative bacilli isolated in the Hospital Torres Galdames, Iquique, Chile}

The antimicrobial resistance is coded in genetic elements which generate a horizontal flow of information, particularly in conditions that are under strong selective pressure like the nosocomial environment. In that sense, in the last decades, gram negative bacilli have become important agents of nosocomial infection. In order to investigate the presence of integrons among clinical isolates of gram negative bacilli and their relationship with their resistance profile, we studied 88 strains isolated from clinical specimens of different wards of the Hospital Torres Galdames, during the June-December period, 2004. They were identified according to biochemical tests. The antimicrobial susceptibility was evaluated by agar diffusion method. The integron presence was investigated by polymerase chain reaction (PCR). A cluster analysis was carried out to study the relationship between the presence of integrons and the resistance profile. The genotyping of the isolates was carried out by ERIC-PCR technique. Results: Of the isolated strains, $18 \%$ corresponded to Proteus mirabilis, $17 \%$ to Escherichia coli, and 32\% to Non Fermentative Gram Negative bacilli. Most isolates presented high resistance to the antibiotics studied: $83 \%$ to ampicillin, $85 \%$ to cephalotin, $82 \%$ to ceftriaxone, $82 \%$ to ciprofloxacin, $81 \%$ to gentamycin and $82 \%$ to cotrimoxazole. Seventy-five $\%$ of the 88 strains presented integrons. Class 2 integrons were found to be the most common. The results of the cluster analysis did not show a clear relationship among the presence of the integrons and the resistance profile. With the available information it is not possible to relate the integron presence with a certain resistance pattern. The patterns of bands obtained with the technique ERIC-PCR revealed a great genetic variety among the analyzed isolations, defining diverse genotypes, distributed in the different services of the hospital where they were isolated.

Key words: Integrons, drug resistance, nosocomial infection, Gram negative bacilli.

Palabras claves: Integrones, resistencia antimicrobiana, infecciones nosocomiales, bacilos gramnegativos.

\section{Introducción}

$\mathrm{E}$ n los últimos treinta años los bacilos gramnegativos han incrementado su importancia, en forma considerable, como agentes causantes de infecciones intrahospitalarias, debido a que han desarrollado fenotipos de resistencia bastante amplios frente a los antimicrobianos ${ }^{1,2}$; situación que también ha sido reportada en Chile por Zemelman y col$^{3}$. Entre ellos destacan integrantes de la familia Enterobacteriaceae ${ }^{4}$, como Escherichia coli, Klebsiella pneumoniae, Serratia marcescens, Enterobacter sp, Proteus sp y bacilos gramnegativos no fermentadores (BGNNF) como Pseudomonas aeruginosa y Acinetobacter baumannii; estos últimos han adquirido gran importancia como patógenos oportunistas ${ }^{5,6}$, debido a su multi-resistencia.

La aparición de resistencia se debe, fundamentalmente, al uso masivo e irracional de los antimicrobianos y selección de clones que presentan esta característica. Actualmente, se conoce que esta multi-resistencia puede estar relacionada a la presencia de integrones ${ }^{7,8}$, los cuales se definen como elementos genéticos que pueden albergar cassettes génicos ${ }^{9}$ que confieren resistencia contra diferentes antimicrobianos. Los integrones codifican una recombinasa de sitio específico que captura y expresa casettes génicos ${ }^{10}$. De acuerdo con la naturaleza de esta recombinasa o integrasa, se han descrito cuatro clases de integrones en bacterias gramnegativas. La existencia de estos elementos 
genéticos favorece una rápida diseminación de la resistencia en cepas que son sometidas a una fuerte presión selectiva, como sucede en el ambiente intrahospitalario.

En la zona norte de Chile son escasos o nulos los estudios realizados con el fin de relacionar la resistencia a los antibacterianos y la presencia de estos elementos genéticos. De acuerdo con estos antecedentes, en este trabajo se consideró investigar la presencia de integrones en bacilos gramnegativos aislados en nuestra institución y establecer su relación con el fenotipo de resistencia a los agentes antibacterianos utilizados en el hospital, así como la diversidad genotípica existente entre los aislados bacterianos.

\section{Material y Métodos}

Se analizaron 88 cepas de bacilos gramnegativos resistentes a antimicrobianos aisladas de pacientes ingresados en el Hospital Regional de Iquique, entre junio y diciembre de 2004 . Sesenta y cuatro por ciento de las muestras correspondió a orinas y $36 \%$ a secreciones. El estudio incluyó las siguientes especies de Enterobacteriaceae: Proteus mirabilis (16), Escherichia coli (15), Klebsiella oxytoca (5), Hafnia alvei (5), Enterobacter agglomerans (3), Klebsiella pneumoniae (2), Klebsiella ozenae (4), Citrobacter freundii (2), Morganella morgagnii (4), otros (5), bacilos gramnegativos no fermentadores (BGNNF): Acinetobacter baumannii (6), Pseudomonas aeruginosa (6) y otros BGNNF (15).

Las cepas fueron identificadas de acuerdo con sus propiedades bioquímicas y mantenidas a $-20{ }^{\circ} \mathrm{C}$, en una mezcla de caldo tripticasa y glicerol $(50 \%)$.

Se determinó el patrón de resistencia a antimicrobianos mediante la técnica de difusión en agar, de acuerdo con lo establecido por el CLSI (Clinical Laboratory Standards Institute, ex NNCLS) ${ }^{11}$, frente a los siguientes antibacterianos: ácido nalidíxico, amikacina, ampicilina, ampicilina/sulbactam, aztreonam, cefadroxilo, cefalotina, cefepime, cefotaxima, ceftazidima, ceftriaxona, cefpodoxima, ciprofloxacina, cloranfenicol, gentamicina, imipenem, meropenem, nitrofurantoína, cotrimoxazol y sulperazona.

Detección de integrones. Se realizó mediante RPC, utilizando partidores específicos para cada clase de integrón (Tabla 1). El templado se obtuvo mediante ebullición, durante 15 minutos, de un cultivo puro, de $10^{9} \mathrm{ufc} / \mathrm{ml}$, se mezcló $400 \mathrm{ml}$ del cultivo con $600 \mathrm{ml}$ de agua nanopura estéril. Tras la ebullición, se centrifugó por cinco minutos a $14.000 \mathrm{rpm}$. La amplificación se realizó en un termociclador Amplitron II, Thermolyne, de acuerdo con el siguiente programa: un ciclo de $96{ }^{\circ} \mathrm{C}$ por 30 segundos, $55^{\circ} \mathrm{C}$ por un minuto, $70{ }^{\circ} \mathrm{C}$ por tres minutos, 25 ciclos de $96{ }^{\circ} \mathrm{C}$ por 15 segundos, $55^{\circ} \mathrm{C}$ por 30 segundos, $70{ }^{\circ} \mathrm{C}$ por tres minutos y una extensión final por cinco minutos ${ }^{9}$. Los productos de la amplificación se detectaron mediante electroforesis en geles de agarosa al $1 \%$, la cual se corrió a $80 \mathrm{~V}$ por $1 \mathrm{~h}$, en tampón TAE $0.5 \mathrm{X}$. El producto de amplificación se visualizó en un transiluminador de luz UV (LabNet), después de haber sido teñido con bromuro de etidio $(0,5 \mathrm{mg} / \mathrm{ml})$.

Análisis de clasificación. Con el fin de relacionar la presencia de integrones y el fenotipo de resistencia, se llevó a cabo un análisis de clasificación, utilizando el índice de distancia de Bray-Curtis. Para el método de análisis y construcción del dendrograma se utilizó la media aritmética no ponderado (UPGMA), lo cual fue realizado sobre datos de presencia-ausencia de resistencia a los antimicrobianos. A partir del dendrograma se definieron los grupos o clusters. Para cada grupo se estimaron los porcentajes de resistencia y la amplitud de resistencia de los antimicrobianos. Para establecer la existencia de diferencias entre los grupos respecto de estos parámetros se realizó un análisis de varianza de una vía no paramétrica.

Genotipificación de las cepas. Se realizó la genotipificación de 58 de las 88 cepas aisladas en el período de estudio, mediante ERIC-PCR ${ }^{12}$. Las cepas fueron agrupadas de acuerdo con su perfil bioquímico en: Acinetobacter, Enterobacter, Hafnia, Klebsiella, BGNNF, Proteus, Pseudomonas y E. coli. La técnica de genotipificación utilizada se basa en la amplificación de secuencias intergénicas de consenso repetitivas de enterobacterias (ERIC-PCR), la cual permite discriminar la diversidad existente entre las cepas aisladas. En este estudio se consideró como genotipo, aislados cuyos perfiles se agrupan en un cluster que presentan una similitud superior a $75 \%^{12}$. La obtención

\begin{tabular}{|c|c|c|}
\hline Nombre & $\begin{array}{l}\text { Secuencia de nucleótidos } \\
\left(5^{\prime} \rightarrow 3^{\prime}\right)\end{array}$ & Clase \\
\hline $\operatorname{lnt} A$ & ATCATCGTCGTAGAGCGTCGG & 1 \\
\hline Int B & GTCAAGGTTCTGGACCAGTTGC & 1 \\
\hline inti2F & GCAAATGAAGTGCAACGC & 2 \\
\hline inti2R & ACACGCTTGCTAACGATG & 2 \\
\hline Intl3 (200) & GCAGGGTGTGACGAATACG & 3 \\
\hline Intl3 (940) & ACAGACCGAGAAGGCTTATG & 3 \\
\hline
\end{tabular}


del templado se realizó mediante ebullición, como se describió anteriormente. Se utilizaron partidores previamente descritos ${ }^{13}$. La amplificación se realizó en un termociclador Amplitron II, Thermolyne, de acuerdo con el siguiente programa: $95^{\circ} \mathrm{C}$ por 5 minutos, cuatro ciclos de $94{ }^{\circ} \mathrm{C}$ por un minuto, $26^{\circ} \mathrm{C}$ por un minuto, 72 ${ }^{\circ} \mathrm{C}$ por dos minutos, 40 ciclos de $94^{\circ} \mathrm{C}$ por 30 segundos, $46^{\circ} \mathrm{C}$ por 30 segundos, $72{ }^{\circ} \mathrm{C}$ por un minuto y una extensión final por 10 minutos a $72{ }^{\circ} \mathrm{C}$. Los productos de la amplificación se detectaron mediante electroforesis en geles de agarosa al 2\%, la cual se corrió a $60 \mathrm{~V}$ por $2 \mathrm{~h}$. Fueron teñidos con bromuro de etidio $(0,5 \mathrm{mg} / \mathrm{ml})$ y se visualizaron en un Transiluminador de luz UV (LabNet).

Análisis de geles y dendogramas. Las imágenes de los geles obtenidos se guardaron como archivos TIFF. Se construyó una matriz de presencia-ausencia de bandas en worpad, que se procesó y analizó mediante el programa TREECON, vers. 1.3b (Universidad de Konstanz, Alemania). Los geles se normalizaron con los marcadores de peso molecular de $100 \mathrm{pb}$ y $1 \mathrm{~kb}$ (Winkler). La construcción de los dendogramas y el nivel de similitud entre los perfiles se calculó mediante el coeficiente de Nei y Li (1979). El análisis de cluster de las matrices de similitud se calculó utilizando el método UPGMA.

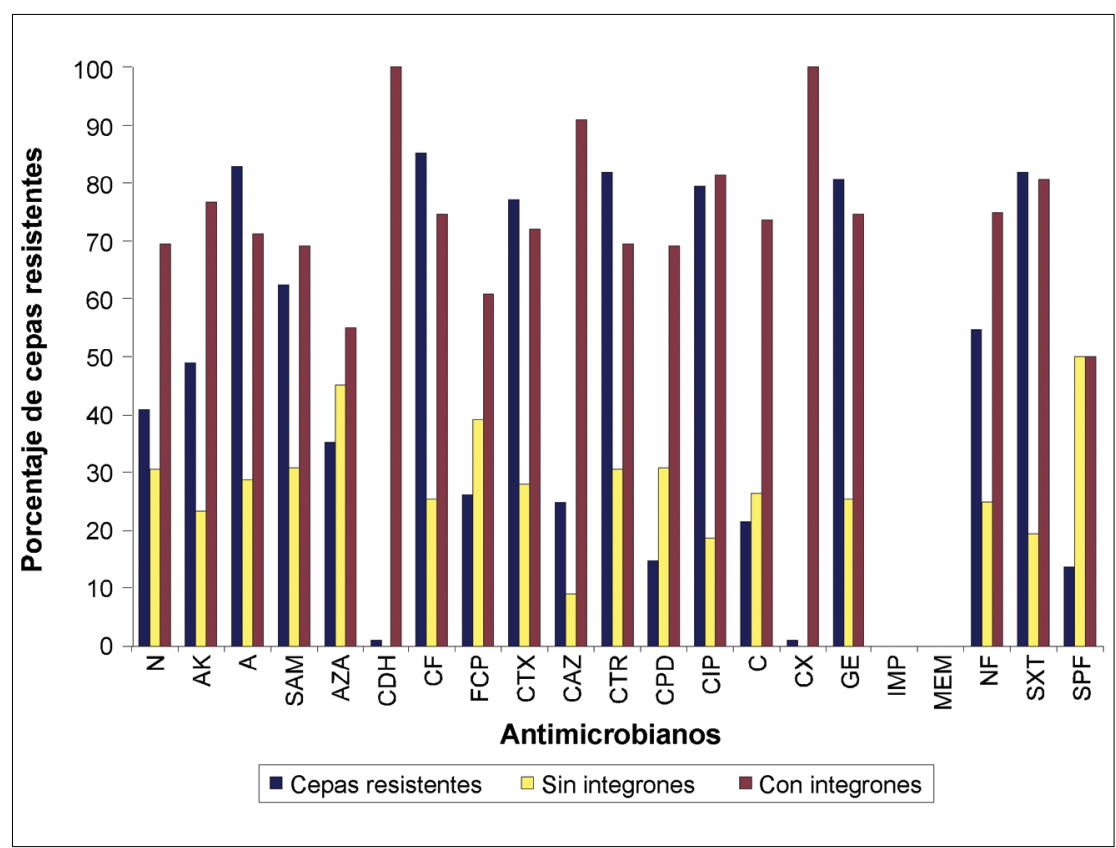

Figura 1. Porcentaje de cepas resistentes a los antimicrobianos ensayados y presencia de integrones. Ácido nalidíxico (N), amikacina (AK), ampicilina (A), ampicilina/sulbactam (SAM), aztreonam (AZA), cefadroxilo $(C D H)$, cefalotina $(C F)$, cefepime $(F C P)$, cefotaxima $(C T X)$, ceftazidima $(C A Z)$, ceftriaxona $(C T R)$, cefpodoxima (CPD), ciprofloxacina (CIP), cloranfenicol (CAF), cloxacilina (CX), gentamicina (G), imipenem (IMP), meropenem (MEM), nitrofurantoína (NF), cotrimoxazol (SXT) y sulperazona (SPZ).

\section{Resultados}

El mayor número de cepas se aisló entre junio y septiembre, concentradas, su mayoría, en los servicios de Cirugía, Medicina, UTI, Urología y Traumatología.

La frecuencia de las distintas clases de integrones determinada en relación con el número total de aislados que presentaron el tipo de integrasa en su genoma, se expresa en la Tabla 2. Setenta y cinco por ciento de las 88 cepas analizadas fueron positivas para la amplificación del gen, siendo prevalente la integrasa clase 2; no se detectaron integrones de clase 3 .

La distribución de integrones por especie bacteriana demostró una mayor frecuencia de ellos en E. coli, $P$. mirabilis, M. morganii, Citrobacter sp, Acinetobacter y otros BGNNF; en cambio se detectaron en un bajo porcentaje de $H$. alvei y $P$. aeruginosa. De las cepas analizadas, $83 \%$ fueron resistentes a ampicilina, $85 \%$, a cefotaxima, $77 \%$ a ceftriaxona, $82 \%$ a ciprofloxacina, $80 \%$ a gentamicina, y $82 \%$ a cotrimoxazol (Figura 2). Las cepas presentaron una amplitud de resistencia que osciló entre 7 y 12 antimicrobianos.

El análisis de cluster reveló que las cepas se dividieron en dos grupos principales, que incluyeron $86 \%$ de ellas $(n=76)$ (Figura 3). El grupo 1 estuvo constituido por un mayor número de cepas $(\mathrm{n}=50)$, encontrándose, preferentemente, M. morganii, BGNNF, A. baumannii, $P$. mirabilis y E. coli. En cambio, el segundo grupo presentó un menor número de cepas $(\mathrm{n}=26)$, sin predominio de alguna especie en particular. Tampoco se observó tendencia alguna respecto de la presencia de integrones en la composición de los grupos.

Globalmente, $75 \%$ de las cepas analizadas evidenciaron la presencia de integrones, lo cual es coincidente con los grupos derivados del análisis de cluster, detectándose la presencia de éstos en $70 \%$ en cada uno de ellos (Tabla 4). Según los resultados obtenidos, se puede sugerir que no existe una diferencia significativa en los patrones de resistencia para bacterias con o sin integrones.

Tabla 2. Frecuencia de integrones en 88 cepas de bacilos gramnegativos estudiados

\begin{tabular}{|lcc|}
\hline Amplicón & No de cepas & \% \\
\hline Sin integrón & 22 & 25 \\
\hline Con integrón & 66 & 75 \\
Clase 1 & 36 & 55 \\
Clase 2 & 54 & 82 \\
\hline Clase $1+2$ & 27 & 41 \\
\hline
\end{tabular}


Del análisis de clonalidad para Acinetobacter, se determinaron dos genotipos entre los aislados, los cuales correspondieron a dos cepas presentes en los servicios de Traumatología y UTI. En Pseudomonas se determinó la presencia de tres genotipos, los cuales corresponden a aislados provenientes de Policlínica y de la Unidad de Respiratorio. Escherichia coli presentó siete genotipos. En términos generales, el estudio reveló una baja clonalidad en las cepas aisladas durante el período de estudio (Figura 3).

\begin{tabular}{|c|c|c|c|c|c|c|c|c|c|c|}
\hline \multirow[b]{2}{*}{ Grupo 1} & \multicolumn{10}{|c|}{ Patrón de resistencia } \\
\hline & G & CTR & $\mathrm{CF}$ & SXT & CIP & A & CTX & SAM & $\mathrm{NF}$ & AK \\
\hline$\%$ resistencia & 100 & 98 & 96 & 96 & 94 & 92 & 86 & 73 & 67 & 63 \\
\hline Grupo 2 & $A$ & $\mathrm{CF}$ & CTR & SXT & CIP & CTX & G & SAM & $\mathrm{NF}$ & AK \\
\hline$\%$ resistencia & 100 & 100 & 100 & 100 & 92 & 88 & 88 & 83 & 71 & 54 \\
\hline
\end{tabular}

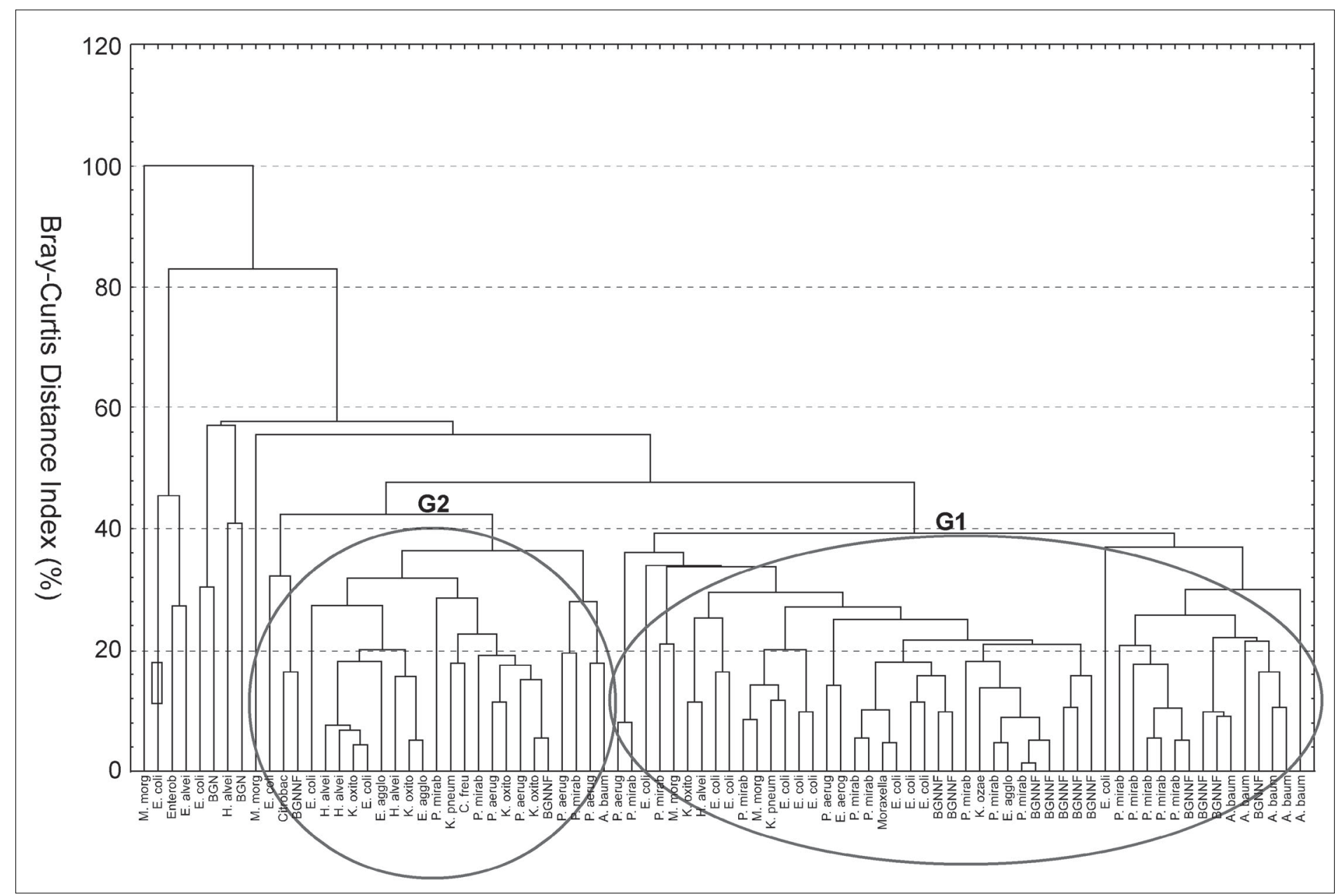

Figura 2. Dendograma del análisis de cluster basado en la susceptibilidad y/o resistencia de las cepas analizadas en relación con los antimicrobianos ensayados. 


\begin{tabular}{|c|c|c|c|c|c|}
\hline Especie & Integrón & Amplitud de resistencia & Clase 1 & Clase 2 & Clase $1+2$ \\
\hline Acinetobacter baumannii & $6 \quad(6)$ & $11 \pm 1$ & $1 \quad(6)$ & $5 \quad(6)$ & (6) \\
\hline BGNNF & $15 \quad(15)$ & $10 \pm 2$ & $7 \quad(15)$ & 11 (15) & $6 \quad(15)$ \\
\hline Citrobacter freundii & $2 \quad(2)$ & $11 \pm 0$ & $1 \quad(2)$ & $2 \quad(2)$ & $(2)$ \\
\hline Enterobacter agglomerans & $2 \quad(3)$ & $11 \pm 1$ & (3) & $2 \quad(3)$ & (3) \\
\hline Escherichia coli & $15 \quad(15)$ & $8 \pm 4$ & 12 (15) & 10 & $6 \quad(15)$ \\
\hline Hafnia alvei & $0 \quad(5)$ & $13 \pm 1$ & (5) & $0 \quad(5)$ & (5) \\
\hline Klebsiella oxytoca & (5) & $10 \pm 2$ & (5) & $0 \quad(5)$ & (5) \\
\hline Klebsiella pneumoniae & $(2)$ & $11 \pm 1$ & $(2)$ & $1 \quad(2)$ & (2) \\
\hline Morganella morganii & (4) & $11 \pm 2$ & (4) & $3 \quad(4)$ & (4) \\
\hline Proteus mirabilis & $15 \quad(16)$ & $10 \pm 3$ & $4 \quad(16)$ & $15(16)$ & $4 \quad(16)$ \\
\hline Pseudomonas aeruginosa & (6) & $10 \pm 2$ & (6) & $1 \quad(6)$ & (6) \\
\hline Otros & (5) & $12 \pm 2$ & (5) & $1 \quad$ (5) & (5) \\
\hline
\end{tabular}

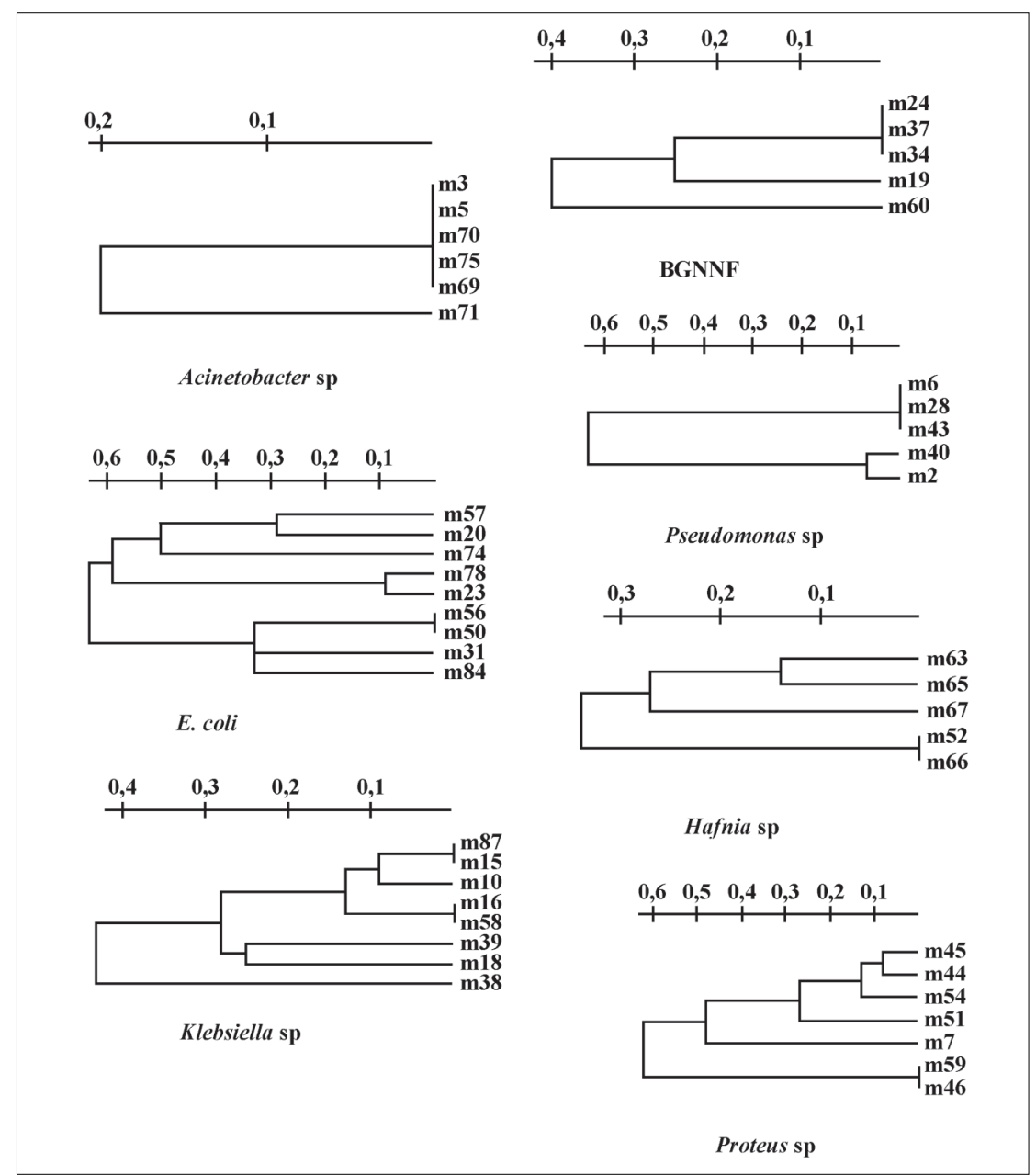

Figura 3. Dendogramas de similitud basado en los perfiles de ERIC-PCR, calculados con el programa TREECON, versión 1b. BGNNF: bacilogamnegativos no fermentados.

\section{Discusión}

Los integrones aparecen como nuevas estructuras que albergan genes de resistencia en los denominados cassettes genéticos, lo que ha permitido la producción de nuevos fenómenos de recombinación y, finalmente, la selección de cepas multi-resistentes en el medio hospitalario ${ }^{14}$.

En este trabajo, alrededor de $80 \%$ de las cepas fueron resistentes a los antimicrobianos ensayados y presentaron, al menos, una clase de integrón, razón por la cual no debe descartarse la importancia de estos elementos en el fenómeno de resistencia. La posible asociación de integrones con otros elementos genéticos móviles como transposones y/o plásmidos pueden explicar, en parte, la multi-resistencia encontrada en los aislados intra-hospitalarios. En futuros estudios es necesario dilucidar cuáles son los cassettes genéticos asociados a los integrones pudiendo así, prever la expresión de multi-resistencia en bacterias que, fenotípicamente, pueden presentarse como susceptibles.

Se debe destacar que las cepas analizadas presentaron un patrón de resistencia amplio a antimicrobianos utilizados en terapia de primera línea, como: ampicilina, ciprofloxacina y cefalosporinas de tercera generación (ceftriaxona $82 \%$ ), lo cual podría generar una disminución en las posibilidades terapéuticas, de continuar diseminándose los genes involucrados en los mecanismos de resistencia. Un porcentaje cercano a $30 \%$ de las cepas presentó resistencia a cefepime. No se detectó resistencia a imipenem ni meropenem. Los servicios que presentaron una elevada presencia de cepas resistentes fueron Medicina, Traumatología y UTI. 
Setenta y cinco por ciento de las cepas estudiadas presentó integrones con una clara prevalencia de los clase 2 , aunque se debe señalar que un número considerable de ellas, presentaba integrones tipo 1 y 2 en forma simultánea.

El análisis de la relación entre la presencia de los integrones, amplitud de resistencia y patrones de resistencia a los antimicrobianos ensayados, reveló que la presencia de estos elementos no tiene incidencia ni en la amplitud ni en el patrón de resistencia observada en las cepas analizadas.

Los integrones se encontraron ampliamente distribuidos en E. coli, P. mirabilis y BGNNF, a excepción de $P$. aeruginosa. Escherichia coli presentó una mayor incidencia de integrones clase 1 , en cambio, $P$. mirabilis mostró una mayor ocurrencia de integrones clase 2 (Tabla 4); no obstante, ambas especies presentaron patrones de resistencia similares. La multi-resistencia se da tanto en cepas que manifiestan la presencia de integrones como aquellas que no, concordando este hecho con los resultados obtenidos del análisis de cluster.

La información obtenida en este estudio permite sugerir que no siempre las características de multiresistencia que presenta una cepa están relacionadas a la presencia de integrones; sin embargo, éstos se encuentran ampliamente diseminados dentro de los bacilos gramnegativos analizados. La mayor presencia de integrones clase 2 encontrada en nuestras cepas, contrasta con resultados obtenidos en E.U.A. y Europa, donde predominan integrones clase $1^{15,16}$.

Con la información expuesta, no es posible relacionar la presencia de integrones con un determinado patrón de resistencia.

Estas estructuras génicas permiten el anclaje o captura de cassettes que portan genes de resistencia, lo cual posibilita una transferencia horizontal de genes. Se ha establecido que los integrones son estructuralmente diversos, pudiendo albergar una gran variedad de genes que codifican resistencia a antimicrobia$\operatorname{nos}^{17,18}$. Por otro lado, se debe recordar que ésta no es la única forma de transferencia horizontal de genes de resistencia, donde elementos como plásmidos, transposones y fagos influyen fuertemente en este tipo de procesos. Esto explicaría, en parte, la alta dispersión de los factores de multi-resistencia tanto en bacterias que presentaron integrones como en aquellas que no.

El análisis de variabilidad genética usando los mar- cadores ERIC-PCR ha sido útil para genotipificar varios géneros de bacterias $^{12,13}$, siendo aplicados con éxito para caracterizar aislados clínicos ${ }^{19,20}$. Los patrones de bandas obtenidos con esta técnica revelaron una gran variedad genética entre los aislados que se analizaron, definiendo diferentes genotipos, distribuidos en los diversos servicios de origen.

\section{Resumen}

La resistencia antimicrobiana es codificada por algunos elementos genéticos que generan un flujo horizontal, particularmente, en ambientes que están sometidos a una fuerte presión selectiva, como ocurre en el ambiente hospitalario. En tal sentido, los bacilos gramnegativos, en el último tiempo, han cobrado importancia como agentes de infección nosocomial. Objetivo. Investigar la presencia de integrones en aislados clínicos de bacilos gramnegativos y su relación con el fenotipo de resistencia, Material y Métodos. Se analizaron 88 aislados clínicos de distintos servicios del Hospital Torres Galdames, durante el período: junio a diciembre de 2004. Fueron identificadas de acuerdo con su perfil bioquímico y se determinó la susceptibilidad a antimicrobianos mediante el método de difusión en agar. La presencia de integrones se detectó mediante RPC. Se realizó un análisis de cluster para estudiar la relación entre el fenotipo de resistencia y la presencia de integrones. Las cepas fueron genotipificadas mediante ERIC-PCR. Resultados. Dieciocho por ciento de las cepas aisladas correspondió a Proteus mirabilis, 17\% a Escherichia coli y $32 \%$ a bacilos gramnegativos no fermentadores. La mayoría de los aislados presentó una elevada resistencia a los antimicrobianos evaluados: ampicilina $83 \%$, cefalotina $82 \%$, ceftriaxona $82 \%$, ciprofloxacina $81 \%$, gentamicina $81 \%$ y cotrimoxazol $82 \%$. De las 88 cepas, $75 \%$ presentó integrones, siendo más común la clase 2 . Los resultados del análisis de cluster no revelaron una clara relación entre la presencia de éstos y el perfil de resistencia para los antimicrobianos ensayados. Con la información disponible no fue posible relacionar la presencia de integrones con un determinado patrón de resistencia. Los patrones de bandas obtenidos con la técnica de ERIC-PCR revelaron una gran variedad genética entre las cepas analizadas, definiendo diversos genotipos, distribuidos en los diferentes servicios de origen de los aislados. 


\section{Referencias}

1.- Lee J, Oh J, Cho J, Park J, Kim J, Seol S, Choo T. The prevalence of trimethoprimresistance-conferring dihydrofolate reductase genes in urinary isolates of $E$. coli in Korea. J Antimicrob Chemother 2001; 47: 599-604.

2.- Kotra L, Hadad J, Mobashery S. Aminoglycosides: perspectives on mechanisms of action and resistance and strategies to counter resistance. Antimicrob Agents Chemother 2000; 4: 3203-5.

3.- Zemelman R, Bello H, Domínguez M, González G, Mella S, García A. Activity of imipenem, third-generation cephalosporins, aztreonam and ciprofloxacin against multiresistant gram-negative isolated from a Chilean hospital. J Antimicrob Chemother 1993; 32: 413-9.

4.- Archibald L, Philips L, Monnet D, McGowan J, Tenover F, Gaines R. Antimicrobial resistance in isolates from inpatiens and outpatiens in the United States-. Increasing importance of the intensive care unit. Clin Infect Dis 1997; 24: 211-5.

5.- Senda K, Arakawa Y, Ichiyama S, Nakashima K, Ito H, Osuka S, et al. Multifocal outbreaks of metallo $\beta$-lactamase producing Pseudomonas aeruginosa resistant to broad spectrum $\beta$ lactams, including carbapenems. Antimicrob Agents Chemother 1996; 40: 349-53.

6.- Bergogne-Bèrèzin $\mathrm{E}$, Towner $\mathrm{K}$. Acinetobacter spp. As Nosocomial pathogens: Most clinical and epidemiological features. Clin Microbol Rev 1996; 9: 148-65.
7.- Reyes A, Bello H, Domínguez M, Mella S, Zemmelman R, González G. Prevalence and types of class 1 integrons in aminoglycosideresistant Enterobacteriacea from several Chilean hospitals. J Antimicrob Chemother 2003; 51: 317-21.

8.- Ramírez C, Pino C, González G, Bello H, Domínguez M, Mella S, et al. Presencia de integrones y su relación con la resistencia a cefalosporinas de tercera generación en cepas de Acinetobacter baumannii de origen nosocomial. Rev Méd Chile 2000; 128: 863-7.

9.- Muñoz J, Bello H, Domínguez M, Mella S, Zemmelman R, González G. Integrones y cassettes genéticos de resistencia a antimicrobianos en cepas de Shigella flexnneri. Rev Méd Chile 2003; 131: 727-33.

10.- Manning P, Clark C, Focareta T. Gene capture in Vibrio cholerae. Trends in Microbiol 1999; 7: 95-9.

11.- National Committee For Clinical Laboratory Standards (NCCLS). 2000. Performance standards for antimicrobial disk susceptibility test. Approved standard. 7th Edition. NCCLS document M2-A7. NCCLS Wayne, Pennsylvania, USA.

12.- Padilla C, Ventura G. Genotipificación de aislamientos de Bartonella bacilliformes por amplificación de elementos repetitivos mediante el uso de REP-PCR y ERIC-PCR. Rev Per Exp Salud Pública 2003; 20: 12831.

13.- Lueng K, Mackereth R, Tien Y-C, Topp E. A comparison of AFLP and ERIC-PCR for discriminating Escherichia coli from cattle, pig and human sources. FEMS Microbiol. Ecol 2004; 47: 111-9

14.- Parrar W. Evolution among antibiotic resistance plasmids in the hospital environment. In: Molecular Biology, Pathogenicity and Ecology of Bacterial Plasmids. Levi S.B., Clows R.C., Koening EL, editors. Plenum Press, New York 1981. $708 \mathrm{pp}$.

15.- Martínez-Freijo P, Fluit A C, Schmitz F J, Grek V S C, Verhoef J, Jones M E. Class I integrons in Gram-negative isolates from different European hospitals and association with decreased susceptibility to multiple antibiotic compounds. J. Antimicrob Chemoth 1998; 42: 689-96.

16.- Schmidt A, Bruun M, Larsen J, Dalsgaard I. Characterization of class 1 integrons associated with R-plasmids in clinical Aeromonas salmonicida isolates from various geographical areas. J Antimicrob Chemother 2001; 47: 735-43.

17.- Gillings M, Holley M P, Stokes H W, Holmes A J. Integrons in Xanthomonas: A source of species genome diversity. Proc Natl Acad Sci 2005; 102: 4419-24.

18.- Chang C, Chang L L, Chang Y H, Lee T M, Chang S F. Characterization of drug resistance gene cassettes associated with class 1 integrons in clinical isolates of Escherichia coli fron Taiwann, ROC. J Med Microbiol 2000; 149: 1097-102.

19.- Soler L, Figueras M, Chacón M, Guerrero J, Martínez-Murcia A. Comparison of three molecular methods for typing Aeromonas popoffii isolates. Antonie Van Leeuvenhock 2003; 83: 341-9.

20.- Versalovic J, Koeuth T, Lupski J. Distribution of repetitive DNA sequences in eubacteria and application to fingerprinting of bacterial genomes. Nucleic Acid Res 1991; 117: 1088-98. 